\title{
Longitudinal study of physical activity in college students: Testing self-determination theory based on stages of change
}

\author{
C. Corella ${ }^{1} \cdot$ A. Abarca-Sos ${ }^{1}$ (D) - L. O. Gallardo ${ }^{1}$ (D) J. Martín-Albo ${ }^{1}$ (D) J. Zaragoza ${ }^{2}$ (D) \\ Accepted: 3 December 2020 \\ (C) The Author(s), under exclusive licence to Springer Science+Business Media, LLC part of Springer Nature 2021
}

\begin{abstract}
The main purpose of this study was to longitudinally test the relationships of Self Determination Theory variables on physical activity, analyzing the model based on stages of change. The study is a longitudinal and quantitative research. We have developed a longitudinal cross-lagged design for structural equation models of three time points and multigroup analysis. Participants were 772 Spanish college students from the University of Zaragoza $(M=19.74, S D=2.76)$ studying several degrees. Participants completed different self-reports, assessing: physical activity, stages of change, motivation and basic psychological needs, at three time points (November, January and March). The analysis indicated that intrinsic motivation positively predicted physical activity at the 3-time points, both directly and indirectly. Intrinsic motivation was negatively predicted by autonomy and positively predicted by competence (from time point 2 to 3 ). No relationships were found with relatedness for the entire sample. Regarding the stages of change multi-group analysis were run: in the low active group, we found a negative relationship between relatedness and physical activity, and a positive association between competence and intrinsic motivation and physical activity, whereas intrinsic motivation did not predict physical activity. Our findings showed that intrinsic motivation was the most consistent predictor of physical activity. The competence need played an essential role in intrinsic motivation and physical activity for both active and passive subjects. However, the basic psychological needs have not worked as indicated by the theory when it was examined longitudinally. The findings of the study highlight the need for different strategies to improve physical activity levels according to the stages of change.
\end{abstract}

Keywords Physical activity $\cdot$ Self-determination theory $\cdot$ Stages of change $\cdot$ College students $\cdot$ Motivation $\cdot$ Basic psychological needs

\section{A. Abarca-Sos \\ aabarca@unizar.es \\ C. Corella \\ criscor@unizar.es \\ L. O. Gallardo \\ lgallardo@unizar.es \\ J. Martín-Albo \\ jmartina@unizar.es \\ J. Zaragoza \\ zaragoza@unizar.es}

1 Faculty of Social Sciences and Humanities, University of Zaragoza, Spain, V C/Ciudad Escolar sn, 44001 Teruel, Spain

2 Faculty of Human Sciences and Education, University of Zaragoza, Spain, Valentín Carderera, 4, 22003 Huesca, Spain

\section{Introduction}

The benefits for health of engaging in physical activity (PA) in adult population are well-documented (Reiner, Niermann, Jekauc, \& Woll, 2013). However, PA patterns decline between the ages of 18 and 24, as many people are studying at college (Grim, Hortz, \& Petosa, 2011).

Transition from the high school stage to the college stage is characterized by a series of changes in lifestyle, such as separation from the family, new housing and new ways of learning (Murphy et al., 2019). PA, as a positive health behavior, has received less attention by researchers than diet or alcohol consumption (Ullrich-French, Smith, \& Cox, 2011). Therefore, PA needs to be analyzed to improve college students' health.

Nowadays, between 60 and $70 \%$ of the college population in Spain has not met the recommendations of PA (Corella, Rodriguez-Munoz, Abarca-Sos, \& Zaragoza, 2018). 
Although, most of the studies developed with this population were cross-sectional, implying little knowledge about the topic (Hagströmer, Kwak, Oja, \& Sjöström, 2015). Therefore, the present study expects to shed light on PA behavior in college students with a longitudinal study design.

\section{Theoretical Framework}

Self Determination Theory (SDT) (Deci \& Ryan, 1985) has been used to explain motivation to engage in PA, and it has gained importance to understand health behaviors (e.g., Teixeira, Carraca, Markland, Silva, \& Ryan, 2012). Moreover, Vallerand (1997) established a Hierarchical Model of Intrinsic and Extrinsic Motivations based on SDT, including the following sequence: basic psychological needs $(\mathrm{BPNs}) \rightarrow$ types of motivation $\rightarrow$ consequences such as PA. In the present study, we have longitudinally tested the model in order to analyze the influence shown in the theory with college students who regularly practice PA versus those who do not.

Self-Determination Mini-Theories Two mini-theories to explain PA have been incorporated: Basic Psychological Needs (BPN) theory and Organismic Integration (OI) theory. Firstly, the BPN theory is integrated by competence, autonomy and relatedness, which must be satisfied to improve motivation related to any behavior (Deci \& Ryan, 2000). Related to PA, competence refers to being effective when doing sports or PA. Autonomy refers to feelings of volition and control of people's behavior. Related to PA, autonomy refers to people's perception of the possibility of making decisions when they do sports or PA. Relatedness is the need to feel a sense of individual acceptance by significant others, connecting with peers in the PA context (Deci \& Ryan, 2000). Finally, in a recent work developed by Ryan and Deci (2020), the authors pointed out that BPN are crucial to students' satisfaction enhance of any behavior.

Secondly, the OI theory establishes motivation as a continuum, integrating it at different levels: intrinsic motivation, extrinsic motivation and amotivation (Deci \& Ryan, 1985). Intrinsic motivation implies an inherent interest in the behavior when the person wants to learn and have fun when participating. It also reflects choice, satisfaction, persistence and the highest self-determination degree. Vallerand (1997) has also considered intrinsic motivation, adding a multidimensional perspective and proposing different typologies: intrinsic motivation to know, intrinsic motivation toward accomplishment, and intrinsic motivation to experience stimulation. Extrinsic motivation refers to engaging in a behavior, because people obtain different and separable results. Nevertheless, intrinsic motivation appears as a powerful regulation to improve PA behavior, because the focus of intervention studies is on creating the conditions to foster and maintain intrinsic motivation levels throughout the program, through BPN promotion (Kinnafick, Thøgersen-Ntoumani, \& Duda, 2014). Moreover, most studies under SDT have not assessed amotivation by comparing it with other regulations, because the negative relationship found with PA in literature is conclusive (Teixeira et al., 2012). The proposed model appears in Fig. 1.

Additionally, to BPN and OI theories of PA behaviors, following the Transtheorical model adds information about the change between PA behavior or non-PA behavior.

Transtheoretical Model (TTM) This is an integrated model of change that should be able to account for the processes that individuals use to change (Prochaska \& Di Clemente, 1982). The TTM provides a framework for understanding PA behavior change and includes five stages of change (SoC) that individuals go through, as a non-linear cyclical process, when they decide to go from being sedentary (no PA behavior) to becoming active (PA behavior) (Rose, Parfitt, \& Williams, 2005). The authors of the model illustrate the stages in a cycle, and suggest that individuals may spiral around the model several times until successful change is achieved (Prochaska \& Di Clemente, 1982). The first two stages are pre-action stages without any actual performance behavior: a) precontemplation: no intention of becoming physically active; b) contemplation: thinking about starting to become physically active within the next 6 months. The next two stages bring a crucial shift in behavioral manifestation: c) preparation: making small changes in behavior but still not meeting a criterion for PA; d) action: meeting a criterion for PA, but only recently - usually within the past 6 months -; e) maintenance: meeting a criterion for PA for 6 months or longer (Norcross, Krebs, \& Prochaska, 2011). The SoC are the central construct of the TTM, encompassing behavior, intentional and temporal aspects of behavior change.

Moreover, combined with SDT, Rose et al. (2005) showed that subjects in the pre-contemplation and contemplation stages were more likely to show less self-determined methods of PA regulation, whereas those in the adoption and maintenance stages had more self-determined methods of PA regulation. Thus, the key question is whether PA-related SDT variables change according to the stages of change?

\section{Previous Studies}

Several previous studies within the PA context have consistently observed that SDT variables are predictors of PA (see the review of Teixeira et al., 2012). Nevertheless, few studies, to date, have developed the theory with college students in relation to PA. And no study has found longitudinal results of the SDT. According to the SDT, Frederick, Morrison, and Manning (1996) found that intrinsic motivation positively predicted perceived competence and satisfaction with PA, 
whereas extrinsic motivation only predicted adherence for men. However, PA behavior was not assessed, and the sample was cross-sectional. Ullrich-Frenck et al. (2011), found that competence, autonomy and relatedness were positively associated with self-determined motivation, which predicts PA, but PA was indirectly predicted by BPNs, and motivational variables were not included in the model. Keshtidar and Behzadnia (2017) concluded that autonomous motivation was positively related to intention to continue carrying out PA, but BPNs were not included in the model, and the data were cross-sectional.

Consequently, although many studies have analyzed PA in the SDT context, in college students, as we have seen, most of them are based on cross-sectional data (e.g. Behzadnia, Adachi, Deci, \& Mohammadzadeh, 2018). Neither BPNs nor motivational regulations were included in the tested models (e.g. Ednie \& Stibor, 2017) and no study has longitudinally analyzed the directionality of the SDT relations (Ersöz \& Eklund, 2017).

Therefore, combined TTM and SDT contribute to improving PA understanding, because participants could present different relationships between SDT variables in each stage of change. However, few researchers have combined these theories. Ersöz and Eklund (2017) pointed out that participants in maintenance stages showed significantly more intrinsic motivation to PA than other stages. However, BPNs were not included, PA behavior was not assessed, and the sample was cross-sectional. Moreover, the results of Farmanbar, Niknami, Lubans, and Hidarnia (2013) showed that the constructs of TTM and SDT (except for external regulation) were significantly related to PA. Nevertheless, the proposed model did not integrate the variables, and the stages of change had no impact on the results. Consequently, one question remains unclear: Can the prediction of STD-based PA behaviors, shown previously, also be confirmed concerning the stages of change in college students?

\section{The Current Study}

To sum up, identifying the relationships between BPNs, the different motivation regulations and PA, is crucial to have a better understanding of the SDT paths throughout time. Moreover, no study in college students has been found to date that follows the sequence developed by Vallerand (1997): basic psychological needs (BPNs) $\rightarrow$ types of motivation $\rightarrow$ PA. Finally, when TTM and SDT are combined, no study has analyzed the relationship variables in agreement with the stages of change.

Therefore, the main purpose of this research was to analyze the SDT longitudinally whereby PA was predicted by intrinsic motivation and BPN, analyzing the relationships by stages of change. It was hypothesized that: a) Satisfying BPN would have a positive effect on intrinsic motivation and PA at subsequent time points. b) Intrinsic motivation would have a positive effect on PA at subsequent time points. c) The structural analysis by stage of change would show invariance, finding differences in SDT variable relationships, principally in lowactive group with less strength in the BPN relationships with intrinsic motivation and PA.

\section{Materials and Methods}

\section{Participants}

The sample comprised 772 Spanish college students from the Teruel Campus of Zaragoza University, located in an urban area, after eliminating 25 participants due to incomplete and missing data in questionnaires. Participants were selected from first and second year students, and from eight degree courses: psychology, business administration and management, primary education, infant education, nursery, arts, computer engineering and electronic engineering. Teruel Campus is characterized by degrees with a higher presence of girls. Therefore, there were more female participants, $604\left(M_{\text {age }}=\right.$ 19.74, $S D=2.76)$ than male, $168\left(M_{\text {age }}=20.33, S D=3.67\right)$. Participants were selected based on criteria of accessibility and willingness to cooperate, after researchers' explanations about the project during class time.

\section{Measures}

Physical Activity The Physical Activity Questionnaire for Adults (PAQ-AD) is a 7-day recall that evaluates moderateto-vigorous PA levels during the previous week (Copeland, Kowalski, Donen, \& Tremblay, 2005). Answers were measured using a 5-point Likert scale in order to assess weekly PA frequency. Participants had to choose one option from the scale for each day and answer the following question: "Mark how often you did physical activity (for example: doing sports, exercise classes, strenuous occupational activity)". The questionnaire was validated in the adult population (Copeland et al., 2005), modifying several activities, eliminating school-related activities, and replacing times of the day (e.g., morning, afternoon). Moreover, the questionnaire was also specifically validated in college students (RodríguezMuñoz, Corella, Abarca-Sos, \& Zaragoza, 2017), showing significant and positive correlations with accelerometer data $(\mathrm{r}=.541$ with counts, $\mathrm{r}=.449$ with uniaxial cut points and $\mathrm{r}=.500$ with triaxial cut points).

Stages of Change To measure this variable, the scale comprising one single item, developed by Cardinal (1995), was used. There are five stages of change in the Transtheoretical Model proposed by Prochaska and Di Clemente (1982): pre- 
contemplation, contemplation, preparation, action and maintenance. Participants had to select one of the 5 options that evaluate the intention to participate in PA and sports in the future (e.g. "I do not exercise and have no interest", pre-contemplation). On this scale, a value from 1 to 5 was assigned to each of the responses, " 1 " being the precontemplation status and " 5 " the maintenance status. The construct validity is supported by the study developed by Cardinal (1995), comparing the results of the questionnaire with energy expenditure in PA and with the peak of $\mathrm{VO}_{2}$ in a physical laboratory test, obtaining significant correlations $(p<.001)$ in both cases.

Motivation The Sport Motivation Scale (SMS: Brière, Vallerand, Blais, \& Pelletier, 1995) was used to assess motivation towards PA and sport. It was validated in Spanish adult population by Núñez, Martín-Albo, and Navarro (2007). The scale is comprised of 28 items with 7 subscales, with a 7-point Likert scale going from does not correspond at all =1, to correspond exactly $=7$. In the present study, we have used 3 subscales comprised of three intrinsic motivation dimensions adapted to PA (Deci \& Ryan, 1985): intrinsic motivation to know subscale (e.g., "For the pleasure it gives me to know more about the physical activity that I practice"), intrinsic motivation to accomplish subscale (e.g., "For the pleasure I feel while improving some of my weak points") and intrinsic motivation to experience stimulation subscale (e.g., "For the pleasure I feel in living exciting experiences"). In our study, the internal consistency of the studied dimensions showed suitable values. Intrinsic motivation to know: T1, $\alpha=.901 ; \mathrm{T} 2, \alpha=.879$; T3, $\alpha=.907$; Intrinsic motivation to accomplish: T1, $\alpha=.902 ; \mathrm{T} 2$, $\alpha=.901 ; \mathrm{T} 3, \alpha=.909$; Intrinsic motivation to experience: T1, $\alpha=.876 ; \mathrm{T} 2, \alpha=.887 ; \mathrm{T} 3, \alpha=.898$.

Basic Psychological Needs The multidimensional questionnaire, Psychological Need Satisfaction in Exercise Scale (PNSE: Wilson, Rogers, Rodgers, \& Wild, 2006), was used to measure psychological need satisfaction. It consists of 6 items for each of the three needs: competence (e.g., "Capable of doing challenging physical activity"), autonomy (e.g. "Free to make my own physical activity decisions") and relatedness (e.g., "Sense of camaraderie with companions") rated on a 5point Likert scale ranging from totally disagree $=1$, to totally agree $=5$. The questionnaire was also validated in the Spanish population (Moreno-Murcia, Marzo, Martínez-Galindo, \& Conte, 2011). Our internal consistency study values showed: Competence: T1, $\alpha=.910, \mathrm{~T} 2, \alpha=.910, \mathrm{~T} 3, \alpha=.924$; Autonomy: T1, $\alpha=.823, \mathrm{~T} 2, \alpha=.861, \mathrm{~T} 3, \alpha=.892$; Relatedness: T1, $\alpha=.852, \mathrm{~T} 2, \alpha=.845, \mathrm{~T} 3, \alpha=.855$.

\section{Procedure}

Firstly, the project was submitted to the Regional Government's Research Ethics Committee and it was approved. Afterwards, students were informed about the voluntary and confidential nature of the study. Moreover, students signed an informed consent in order to participate in the study. The questionnaires were administered at 3 time points. In October 2015 (T1), January 2016 (T2) and April 2016 (T3), with a 3 months' gap in order to assess the changeability of variables. The questionnaires took approximately $25 \mathrm{~min}$ to complete each time, and they were given out during regular lessons by researchers and trained assistants. The study is a longitudinal and quantitative research.

\section{Statistical Analysis}

Data were analyzed with Mplus, Version 7.11 in order to implement a cross-lagged panel design with three time points and structural equation modeling. Parcels were configured for each variable to reduce sampling errors, decreasing the specific variances of each item. Parcels were configured following the recommendations of Little, Rhemtulla, Gibson, and Schoemann (2013). Items were randomly assigned to parcels and then averaged. In addition, to precisely define the constructs (Little et al., 2013), a just-identified measurement space was created, and each latent construct was based on 3 parcels. PA was the exception, which was calculated following the questionnaire validation protocol (Copeland et al., 2005).

To compare groups, the assumption that the instruments measure the same psychological construct at all times and in all groups must be held. If this assumption is held, the comparisons are valid and the differences/similarities/variations between groups can be meaningfully interpreted (Milfont \& Fischer, 2010). So, longitudinal factorial invariance was tested as a prerequisite to assess the cross-lagged structural models. In order to do so, an unconstrained model was established and hierarchically advanced to more restricted (and nested) models (Little et al., 2013). The invariance routine started by testing the unconstrained model, in which the pattern of indicator-to-construct is equal across time points (configural invariance). This baseline model was subsequently compared with the next level of measurement invariance, including factor loading equality (weak factorial invariance), equality of the intercepts of the corresponding indicators (strong factorial invariance), and equality of the residual variances of the corresponding indicators (strict factorial invariance). The models involved the residuals of the corresponding indicators being allowed to correlate across time points. The first factor loading per latent variable was set to unity to establish the scale of latent variables, as recommended by Little, Preacher, Selig, and Card (2007). "A value of $\Delta$ CFI smaller than or equal to 0.01 indicates that the null hypothesis of invariance 
should not be rejected" (Cheung \& Rensvold, 2002, p. 251). Consequently, 3 fully cross-lagged panel models were tested. The first one assessed whether BPNs and intrinsic motivation influence PA among college students (see Fig. 1). The model includes the entire sample. In addition, indirect effects of $\mathrm{T} 1$, competence, autonomy, relatedness, and intrinsic motivation, on T2, PA, were tested with the Mplus MODEL INDIRECT procedure. Additionally, the model was replicated (the second one), although only with the sample of low-active college students. The low-active group was created with the participants of the precontemplation, contemplation and preparation stages, following the original concept (Prochaska \& Di Clemente, 1982). The precontemplation and contemplation stages are intentional, but behavioral change does not appear, preparation has both intentional and behavioral change, although PA has not reached the recommendations (Norcross et al.,
2011). With that categorization, we get two groups: one of active people who reach $\mathrm{PA}$ recommendations, and another with low-active people who do not. Finally, (the third model) was again replicated although only with the active sample. It includes the stages of action and maintenance that reached $\mathrm{PA}$ recommendations (Norcross et al., 2011) (Fig. 1).

In agreement with the possible multivariate nonnormality of the measures, the robust maximum likelihood (MLR) estimator was selected for model estimations (Wang \& Wang, 2012). Goodness-of-fit was tested with common fit indexes. Thus, a model fit is considered adequate when the Comparative Fit Index (CFI) and the Tucker-Lewis Index (TLI) have values of $>0.90$, the Root Mean Square Error of Approximation (RMSEA) is $<0.06$, and the Standardized Root Mean Square Residual (SRMR) is $<0.08$ (Iacobucci, 2010).

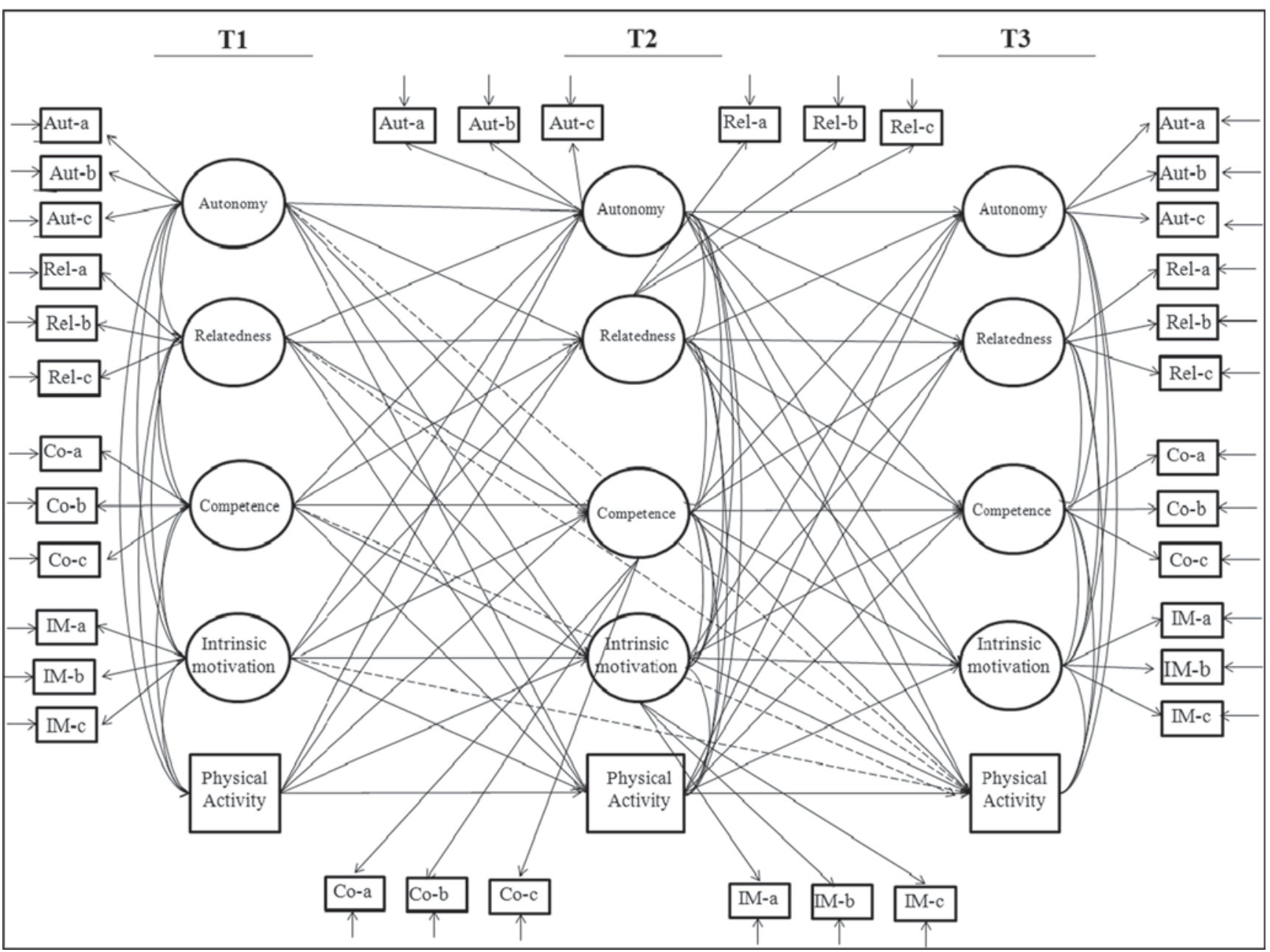

Fig. 1 Structural model proposed to be tested. Abbreviations were used in parcels in order to clarify the figure (Autonomy: Aut; Relatedness: Rel; Competence: Co; Intrinsic Motivation: IM; Physical Activity: PA). The tested model is comprised by the relationships between variables through the three times, correlations in each time and the parcels to create the latent variables. PA was an observed variable 


\section{Results}

The models, after conducting the parceling procedure, were made up of competence, autonomy, relatedness, and intrinsic motivation, treated as 4 latent variables (each one comprised of 3 parcels), with PA as an observed variable. Longitudinally, 12 latent variables (36 parcels) and 3 observed variables were examined in all. First, we ran the model with the entire sample, then with low-active college students, and finally with the active sample.

Descriptive statistics and the correlation matrix between the model variables are shown in Table 1. All correlations are positive and significant between the variables, both cross-sectionally and longitudinally.

Participants were categorized into the first three stages, precontemplation, contemplation and preparation. Those associated with insufficient PA levels (Prochaska \& Di Clemente, 1982) were placed in a low-active group, and students in the action and maintenance stages were placed in an active group (Prochaska \& Di Clemente, 1982). Results show that the active group reached a significantly higher level of PA at the three time points $\left[F_{t 1}(1769)=2015.55 p<.001 ; F_{t 2}(1769)=2017.01 p<.001\right.$; $\left.F_{t 3}(1769)=2044.68 p<.001\right]$ than the low-active group.

\section{Previous Analysis: Invariance Testing}

Tests of longitudinal factorial invariance are presented in Table 2. A decrease in CFI $<0.01$ implies invariance. Thus, according to this criterion, weak factorial invariance was supported by comparisons across time points. This implies that the measures have equivalent relationships between indicators and latent factors across time points (equality of factor loadings). Thus, comparisons are valid, and differences and similarities between the entire sample, including low-active and active groups, can be meaningfully interpreted.

\section{The Proposed Cross-Lagged Panel Models}

The structural model, with the entire sample, presented an acceptable fit to the data according to RMSEA and SRMR indexes $\left(\chi^{2}=3078.846, d f=625\right.$; CFI $=.890, \mathrm{TLI}=.870$, RMSEA $=.058,90 \%$ CI $[.059, .064]$, SRMR $=.060)$. All autoregressive regression weights were positive and strong (all $p \mathrm{~s}<.01$ ), denoting that individuals' relative scores in the variables had changed very little over time (stability over time of the variables).

Moreover, the indirect effects of the variables measured at the initial time point (T1) were explored, comparing them with PA at time point 3 (T3). Analyses revealed only one specific significant indirect effect from intrinsic motivation at time point 1 (T1) towards PA at time point 3 (T3), through intrinsic motivation at time point 2 (T2) $(\beta=0.079,95 \%$ CI [.035, 2.283], $p=.022)$.

The structural model with the sample of low-active college students $(N=409)$ presented an adequate fit to the data according to the RMSEA and SRMR indexes $\left(\chi^{2}=1869.308, d f=\right.$ 625; $\mathrm{CFI}=.890, \mathrm{TLI}=.870, \mathrm{RMSEA}=.057,90 \%$ CI [.056, $.063]$, SRMR $=.058$ ), although worse than the structural model with the entire sample. All autoregressive regression weights

Table 1 Means, standard deviations, and correlations between latent and observed variables

\begin{tabular}{|c|c|c|c|c|c|c|c|c|c|c|c|c|c|c|c|c|c|c|}
\hline & \multirow[t]{2}{*}{ Variables } & \multirow[t]{2}{*}{$M$} & \multirow[t]{2}{*}{$S D$} & \multicolumn{5}{|l|}{$\mathrm{T} 1$} & \multicolumn{5}{|l|}{$\mathrm{T} 2$} & \multicolumn{5}{|l|}{$\mathrm{T} 3$} \\
\hline & & & & 1 & 2 & 3 & 4 & 5 & 6 & 7 & 8 & 9 & 10 & 11 & 12 & 13 & 14 & 15 \\
\hline \multirow[t]{5}{*}{$\mathrm{T} 1$} & 1 Autonomy & 4.47 & .99 & - & & & & & & & & & & & & & & \\
\hline & 2 Relatedness & 3.70 & 1.25 & .557 & - & & & & & & & & & & & & & \\
\hline & 3 Competence & 4.10 & 1.20 & .867 & .664 & - & & & & & & & & & & & & \\
\hline & 4 Intrinsic motivation & 4.14 & 1.64 & .694 & .622 & .715 & - & & & & & & & & & & & \\
\hline & 5 Physical activity & 2.29 & .91 & .398 & .512 & .471 & .505 & - & & & & & & & & & & \\
\hline \multirow[t]{5}{*}{$\mathrm{T} 2$} & 6 Autonomy & 4.22 & 1.09 & .566 & .225 & .406 & .309 & .205 & - & & & & & & & & & \\
\hline & 7 Relatedness & 3.41 & 1.18 & .344 & .473 & .367 & .400 & .267 & .631 & - & & & & & & & & \\
\hline & 8 Competence & 3.90 & 1.17 & .499 & .251 & .557 & .398 & .241 & .951 & .597 & - & & & & & & & \\
\hline & 9 Intrinsic motivation & 4.07 & 1.50 & .441 & .346 & .448 & .581 & .362 & .598 & .631 & .636 & - & & & & & & \\
\hline & 10 Physical activity & 1.97 & .89 & .222 & .172 & .260 & .278 & .439 & .194 & .259 & .214 & .322 & - & & & & & \\
\hline \multirow[t]{5}{*}{$\mathrm{T} 3$} & 11 Autonomy & 4.28 & 1.10 & .308 & .114 & .180 & .161 & .133 & .527 & .304 & .404 & .601 & .195 & - & & & & \\
\hline & 12 Relatedness & 3.45 & 1.21 & .183 & .284 & .258 & .280 & .198 & .287 & .569 & .362 & .449 & .268 & .597 & - & & & \\
\hline & 13 Competence & 3.95 & 1.21 & .256 & .148 & .326 & .257 & .188 & .410 & .311 & .533 & .418 & .301 & .888 & .572 & - & & \\
\hline & 14 Intrinsic motivation & 4.04 & 1.57 & .244 & .219 & .307 & .347 & .235 & .334 & .417 & .444 & .573 & .387 & .641 & .546 & .624 & - & \\
\hline & 15 Physical activity & 2.27 & .92 & .153 & .121 & .175 & .195 & .202 & .198 & .228 & .241 & .317 & .387 & .301 & .259 & .336 & .351 & - \\
\hline
\end{tabular}

Significant correlations appear in bold type. $N=772$ 
Table 2 Longitudinal factorial invariance analysis of the measurement model, and test of equality of latent means across time points

\begin{tabular}{lllllllll}
\hline Invariance measurement test & $\chi^{2}$ & df & RMSEA & SRMR & TLI & CFI & $\Delta$ CFI & $\Delta$ model \\
\hline Configural invariance & 3482.478 & 631 & .077 & .109 & .836 & .860 & & \\
Weak factorial invariance & 3525.410 & 647 & .076 & .109 & .838 & .859 & -0.001 & 2 vs. 1 \\
Strong factorial invariance & 3852.040 & 663 & .079 & .110 & .825 & .844 & -0.015 & 3 vs. 2 \\
Strict factorial invariance & & & & & & & & \\
\hline
\end{tabular}

ұ2: Chi-square test; $d f$, degrees of freedom; RMSEA, Root Mean Square Error of Approximation; SRMR, Standardized Root Mean Square Residual; TLI, Tucker-Lewis; Index; CFI, Comparative Fit Index; $\triangle C F I$, variations in $\mathrm{CFI}$

were positive and strong (all $p \mathrm{~s}<.01)$. Nevertheless, looking at the other model paths, these were only significant when: Competence at T1 predicted PA at T2 $(\beta=0.257, p=.049)$; Competence at $\mathrm{T} 2$ predicted intrinsic motivation at $\mathrm{T} 3(\beta=$ $0.276, p=.022)$; Relatedness at $\mathrm{T} 1$ predicted competence at $\mathrm{T} 2(\beta=-0.137, p=.028)$ and PA at T2 $(\beta=-0.160, p=.004)$.

Finally, the structural model with the sample of active college students did not converge and it could not be analyzed (Fig. 2).

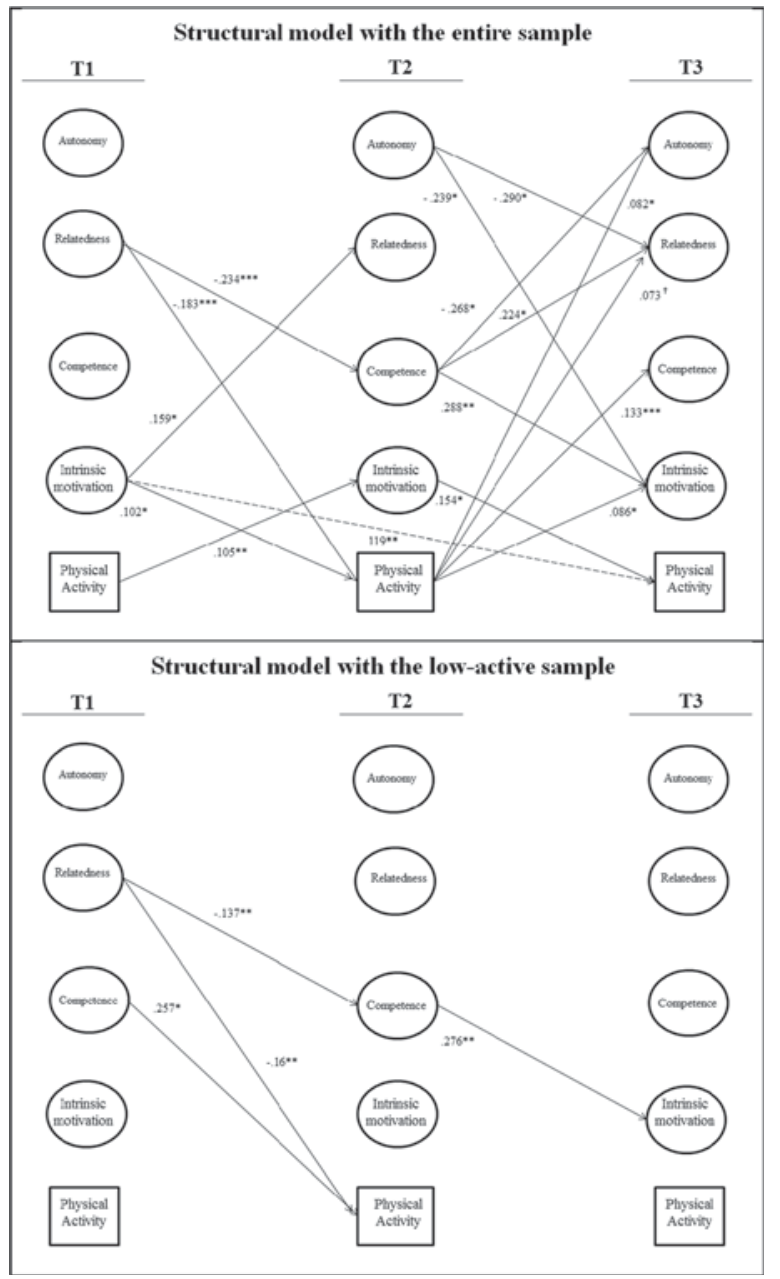

Fig. 2 Structural models with the entire sample and with the low-active sample. Standardized parameters examining the relationships between BPNs, intrinsic motivation and PA. Covariances, correlations and nonsignificant paths in the structural model are omitted for presentation clarity. ${ }^{* * *} p<.001,{ }^{* *} p<.01,{ }^{*} p<.05,{ }^{\dagger} p<.10$

\section{Discussion}

The aim of this study was to test the SDT theory by developing a longitudinal model where physical activity was predicted at time points 2 and 3 by intrinsic motivation and basic psychological needs, analyzing the relationships by stage of change.

According to hypothesis 1, in relation to the entire sample, satisfying BPN would have a positive effect on intrinsic motivation and PA at subsequent times. Our results showed that at time points 1 and 2 there were no significant associations between BPN and intrinsic motivation. However, from time point 2 to time point 3 , intrinsic motivation was predicted by two of the BPNs, negatively by autonomy and positively by competence, while no relationships were found with relatedness. The sequence developed by Vallerand (1997) pointed out that BPNs have a positive influence on intrinsic motivation as a psychological mediator of PA behavior. Moreover, different studies have empirically demonstrated these positive relationships (e.g., McDonough \& Crocker, 2007; Ullrich-Frenck et al., 2011). Nevertheless, not all BPNs influence intrinsic motivation or other variables in the same manner. Besides, most studies are cross-sectional, implying that the relationships shown by these works must be considered with caution in terms of comparisons. The results of Standage, Gillison, Ntoumanis, and Treasure (2012), in children, and Yu et al. (2015) in the adult population, are consistent with our study, showing that relatedness did not predict intrinsic motivation. Perhaps in a context of secure relationships, this BPN may not be as reliant on proximal supports to their volitional conduct (Standage et al., 2012). Related to autonomy, McDonough and Crocker (2007), this BPN showed weak relationships to intrinsic motivation. In our study, autonomy is negatively associated with intrinsic motivation between time point 2 and time point 3 , and no relationship was found from time point 1 to time point 2. This unexpected result for the entire sample could be caused by measurement issues in the autonomy subscale of the PNSE, because the items have not captured autonomy satisfaction in different circumstances (McDonough \& Crocker, 2007). Likewise, Teixeira et al. (2012) showed that perceived autonomy positively predicted identified regulation to a 
greater extent than intrinsic motivation. Thus, introducing identified regulation into the intrinsic motivation variable in our study could have improved the relationship between autonomy and intrinsic motivation.

In our study, competence was positively associated with intrinsic motivation, according to the theory (Deci \& Ryan, 1985) and several studies (Gunnell, Crocker, Mack, Wilson, \& Zumbo, 2014; McDonough \& Crocker, 2007). Competence plays an essential role in motivation toward PA, because it is related to effort, and the intention to be physically active (Taylor, Spray, Ntoumanis, \& Standage, 2010).

Secondly, physical activity is not related to BPNs at any of the time points, except for the period between time points 1 and 2, where relatedness showed a negative relationship. Different studies (Gunnell et al., 2014; McDonough \& Crocker, 2007) have shown that competence plays an important role in physical activity or exercise frequency, but not in autonomy or relatedness. Additionally, some researchers included other emotional consequences in the model, such as for instance self-esteem (Fernández-Ozcorta, Almagro, \& SáenzLópez, 2014), but not behavior. Thus, BPNs are more highly related to the emotional consequences of the SDT sequence, such as psychological variables (Vallerand, 1997) than to the behavioral consequences, such as PA.

Results may suggest that, longitudinally, BPNs have not functioned properly as predictors of intrinsic motivation and PA. Therefore, it is necessary to understand the role of each need in the motivational process through more longitudinal studies.

Continuing with the second hypothesis for the entire sample, high levels of intrinsic motivation have a positive effect on PA, and our results supported this relationship. Intrinsic motivation positively predicted PA from $\mathrm{T} 1$ to $\mathrm{T} 2$, from $\mathrm{T} 2$ to T3, and from T1 to T3. These findings are in agreement with SDT, which states that intrinsic motivation causes important behavioral consequences, such as PA (Vallerand, 1997). Our results have been mirrored in other studies (e.g., Ingledew \& Marklan, 2008). Thus, adults that internalize PA behavior are more engaged (Sicilia et al., 2014) and improve their health, because intrinsic motivation predicted moderate-tovigorous PA (Silva et al., 2010). Moreover, these longitudinal findings are essential to corroborate SDT because intrinsic motivation is especially important for longer term exercise participation (Teixeira et al., 2012). From a practical perspective, the present research suggests that strategies must be designed to promote intrinsic motivation in order to improve PA behavior.

Related to hypothesis 3, where the model was run with the low-active participants, results showed differences in the SDT variables relationships. First, intrinsic motivation did not predict the practice of PA in low-active college students (in the stages of pre-contemplation, contemplation and preparation). These results have been seen in other studies. Ersöz and
Eklund (2017), for example, found that students in the maintenance stage of change displayed more self-determined motivation to exercise than those in early stages.

Second, the competence need was found to be the strongest predictor of intrinsic motivation and PA, as shown in the general model of our study (McDonough \& Crocker, 2007). Farmanbar et al. (2013) showed, with university students, that self-efficacy, as a similar construct to competence, was a predictor of exercise behavior. Therefore, competence plays an important role in intrinsic motivation and PA, for both active and low-active subjects.

Third, low-active college students, related to insufficient PA, have a negative perception of relatedness when they practice PA. In our general model, relatedness, from time point 1 to time point 2 , showed a negative relationship with PA. This result could be caused by younger adults who are more likely to participate in PA for external reasons, for example: physical appearance, body image... placing little importance on social relationships (Ingledew \& Marklan, 2008). Also, Brunet and Sabiston (2011) suggested that adults depend more on introjected regulation for (extrinsic motivation type) PA participation. Another reason for this result could be the lack of social support previously experienced by students in relation to the practice of PA (Gómez-López, Gallegos, \& Extremera, 2010). Finally, this finding may suggest that students in preparation stage (doing PA irregularly) perceived relatedness in a negative way. Therefore, improving relationships with peers could be an important strategy to change to the action stage.

\section{Limitations}

Despite this study providing longitudinal information about SDT sequences related to PA and stages of change, there are several limitations that should be mentioned.

Firstly, we decided to include intrinsic motivation and not other regulations in the intrinsic motivation dimension (e.g., identified regulation). This could complicate comparisons between studies and even modify relationships in the motivational process. Secondly, data were collected using a selfreport measure for PA. Thus, the subjective measurement may underestimate or overestimate the PA levels (Downs, Van Hoomissen, Lafrenz, \& Julka, 2014). Thirdly, social influence (e.g., autonomy support) should be analyzed as a determining factor of BPNs, and as fundamental nutriments to high quality motivation (Standage et al., 2012), because social environment support the BNP to improve PA (Ryan \& Deci, 2020).

\section{Conclusions}

This study has longitudinally examined the SDT sequence, extending the findings to PA behavior and its relationship to 
the theory of stages of change, in college students. Results have shown the importance of intrinsic motivation in PA behavior, mainly for the entire sample, because the low-active group has not shown relationships between these variables. No study has longitudinally tested these relationships. Thus, these findings corroborate SDT construct and also highlight that intrinsic motivation is crucial for longer term PA behavior. Moreover, competence played an essential role, because low-active groups have shown positive relationships with intrinsic motivation and PA, compared with autonomy and relatedness. Therefore, findings highlight that strategies must be designed that promote intrinsic motivation and competence in order to improve PA behavior. For instance, and following SDT constructs (Deci \& Ryan, 1985), competence could be enhanced in an intervention program by designing activities that include simple to more complex skills, providing a taskoriented climate during PA practice, or using positive reinforcement to recognize effort and individual progress. Moreover, in the same context, intrinsic motivation could be improved, increasing knowledge about PA guidelines in order to understand the benefits, or developing activities based on participants' enjoyment.

Future studies should combine the constructs of SDT and TTM to explain the exercise behavior of college students and to design effective intervention programs, because the nature of PA is complex and dynamic. For example, selecting participants in contemplation or preparation stages (they have the intention to be engaged in PA but they are not sufficiently active) and developing an intervention program that supports BPNs.

Acknowledgements This work was supported by the Antonio Gargallo Foundation, University of Zaragoza in Teruel, and Ibercaja bank.

\section{Compliance with Ethical Standards}

On behalf of all authors, the corresponding author states that there is no conflict of interest. The datasets generated during and/or analysed during the current study are available from the corresponding author on reasonable request. This work has been approved by the ethics committee of research of the Aragon region (Spain). All participants have signed informed consent to participate in the study.

\section{References}

Behzadnia, B., Adachi, P. J., Deci, E. L., \& Mohammadzadeh, H. (2018). Associations between students' perceptions of physical education teachers' interpersonal styles and students' wellness, knowledge, performance, and intentions to persist at physical activity: A selfdetermination theory approach. Psychology of Sport and Exercise, 39, 10-19. https://doi.org/10.1016/j.psychsport.2018.07.003.

Brière, N. M., Vallerand, R. J., Blais, M. R., \& Pelletier, L. G. (1995). Development and validation of a measure of intrinsic, extrinsic, and amotivation in sports: The sport motivation scale (SMS). International Journal of Sport Psychology, 26, 465-489.
Brunet, J., \& Sabiston, C. M. (2011). Exploring motivation for physical activity across the adult lifespan. Psychology of Sport and Exercise, 12(2), 99-105. https://doi.org/10.1016/j.psychsport.2010.09.006.

Cardinal, B. J. (1995). The stages of exercise scale and stages of exercise behavior in female adults. Journal of Sports Medicine \& Physical Fitness, 35(2), 87-92.

Cheung, G. W., \& Rensvold, R. B. (2002). Evaluating goodness-of-fit indexes for testing measurement invariance. Structural Equation Modeling, 9, 233-255. https://doi.org/10.1207/ S15328007SEM0902_5.

Copeland, J. L., Kowalski, K. C., Donen, R. M., \& Tremblay, M. S. (2005). Convergent validity of the physical activity questionnaire for adults: The new member of the PAQ family. Journal of Physical Activity and Health, 2(2), 216-229. https://doi.org/10. 1123/jpah.2.2.216.

Corella, C., Rodriguez-Munoz, S., Abarca-Sos, A., \& Zaragoza, J. (2018). Compliance of physical activity guidelines depending on cutoffs points and gender in Spanish university students. Sport TK-Revista Euroamericana de Ciencias del Deporte, 7(1), 9-17.

Deci, E. L., \& Ryan, R. M. (1985). Intrinsic motivation and selfdetermination in human behavior. New York: Plenum.

Deci, E., \& Ryan, R. (2000). The "what" and "why" of goal pursuits: Human needs and the self-determination of behavior. Psychological Inquiry, 11, 227-268. https://doi.org/10.1207/S15327965PLI1104_ 01.

Downs, A., Van Hoomissen, J., Lafrenz, A., \& Julka, D. L. (2014). Accelerometer-measured versus self-reported physical activity in college students: Implications for research and practice. Journal of American College Health, 62(3), 204-212.

Ednie, A., \& Stibor, M. (2017). Influence and interpretation of intrinsic and extrinsic exercise motives. Journal of Human Sport and Exercise, 12(2), 414-425. https://doi.org/10.14198/jhse.2017.122. 18.

Ersöz, G., \& Eklund, R. C. (2017). Behavioral regulations and dispositional flow in exercise among American college students relative to stages of change and gender. Journal of American College Health, 65(2), 94-102. https://doi.org/10.1080/07448481.2016.1239203.

Farmanbar, R., Niknami, S., Lubans, D. R., \& Hidarnia, A. (2013). Predicting exercise behaviour in Iranian college students: Utility of an integrated model of health behaviour based on the transtheoretical model and self-determination theory. Health Education Journal, 72(1), 56-69. https://doi.org/10.1177/ 0017896911430549.

Fernández-Ozcorta, E. J., Almagro, B. J., \& Sáenz-López, P. (2014). Explanatory model of psychological well-being in the university athletic context. Procedia-Social and Behavioral Sciences, 132, 255-261. https://doi.org/10.1016/j.sbspro.2014.04.307.

Frederick, C. M., Morrison, C., \& Manning, T. (1996). Motivations to participate, exercise affect, and outcome behaviors toward physical activity. Perceptual and Motor Skills, 82(2), 691-701. https:/doi. org/10.2466/pms.1996.82.2.691.

Gómez-López, M., Gallegos, A. G., \& Extremera, A. B. (2010). Perceived barriers by university students in the practice of physical activities. Journal of sports science \& medicine, 9(3), 374-381.

Grim, M., Hortz, B., \& Petosa, R. (2011). Impact evaluation of a pilot web-based intervention to increase physical activity. American Journal of Health Promotion, 25(4), 227-230.

Gunnell, K. E., Crocker, P. R., Mack, D. E., Wilson, P. M., \& Zumbo, B. D. (2014). Goal contents, motivation, psychological need satisfaction, well-being and physical activity: A test of self-determination theory over 6 months. Psychology of Sport and Exercise, 15(1), 1929. https://doi.org/10.1016/j.psychsport.2013.08.005.

Hagströmer, M., Kwak, L., Oja, P., \& Sjöström, M. (2015). A 6 year longitudinal study of accelerometer-measured physical activity and sedentary time in Swedish adults. Journal of Science and Medicine 
in Sport, 18(5), 553-557. https://doi.org/10.1016/j.jsams.2014.07. 012.

Iacobucci, D. (2010). Structural equations modeling: Fit indices, sample sizes, and advanced topics. Journal of Consumer Psychology, 20(1), 90-98. https://doi.org/10.1016/j.jcps.2009.09.003.

Ingledew, D. K., \& Marklan, D. (2008). The role of exercise motives in exercise participation. Psychology \& Health, 23(7), 807-828. https://doi.org/10.1080/08870440701405704.

Kinnafick, F. E., Thøgersen-Ntoumani, C., \& Duda, J. L. (2014). Physical activity adoption to adherence, lapse, and dropout: A selfdetermination theory perspective. Qualitative Health Research, 24(5), 706-718.

Keshtidar, M., \& Behzadnia, B. (2017). Prediction of intention to continue sport in athlete students: A self-determination theory approach. PLoS One, 12(2), e0171673. https://doi.org/10.1371/journal.pone. 0171673.

Little, T. D., Preacher, K. J., Selig, J. P., \& Card, N. A. (2007). New developments in latent variable panel analyses of longitudinal data. International Journal of Behavioral Development, 31, 357-365. https://doi.org/10.1177/0165025407077757.

Little, T. D., Rhemtulla, M., Gibson, K., \& Schoemann, A. M. (2013). Why items versus parcels controversy needn't be one. Psychological Methods, 18(3), 285-300.

Milfont, T. L., \& Fischer, F. (2010) Testing measurement invariance across groups: applications in cross-cultural research. International Journal of Psychological Research, 3(1), 111-130. https://doi.org/ 10.21500/20112084.857.

McDonough, M. H., \& Crocker, P. R. (2007). Testing self-determined motivation as a mediator of the relationship between psychological needs and affective and behavioral outcomes. Journal of Sport and Exercise Psychology, 29(5), 645-663. https://doi.org/10.1123/jsep. 29.5.645.

Moreno-Murcia, J. A., Marzo, J. C., Martínez-Galindo, C., \& Conte, L. (2011). Validation of psychological need satisfaction in exercise scale and the Behavioural regulation in sport questionnaire to the Spanish context. RICYDE. International Journal of Sport Science, 7(26), 355-369. https://doi.org/10.5232/ricyde2011.02602.

Murphy, J. J., MacDonncha, C., Murphy, M. H., Murphy, N., Nevill, A. M., \& Woods, C. B. (2019). What psychosocial factors determine the physical activity patterns of university students? Journal of Physical Activity \& Health, 16(5), 325-332. https://doi.org/10. 1123/jpah.2018-0205.

Norcross, J. C., Krebs, P. M., \& Prochaska, J. O. (2011). Stages of change. Journal of Clinical Psychology, 67(2), 143-154. https:// doi.org/10.1002/jclp.20758.

Núñez, J. L., Martín-Albo, J., \& Navarro, J. G. (2007). Propiedades psicométricas de la versión española de la escala de motivación deportiva. Revista De Psicología Del Deporte, 16(2), 211-223.

Prochaska, J. O., \& Di Clemente, C. C. (1982). Transtheoretical therapy: Toward a more integrative model of change. Psychotherapy: Theory, Research \& Practice, 19(3), 276-288.

Reiner, M., Niermann, C., Jekauc, D., \& Woll, A. (2013). Long-term health benefits of physical activity-a systematic review of longitudinal studies. BMC Public Health, 13(1), 813. https://doi.org/10. 1186/1471-2458-13-813.

Rodríguez-Muñoz, S., Corella, C., Abarca-Sos, A., \& Zaragoza, J. (2017). Validation of three short physical activity questionnaires with accelerometers among university students in Spain. The Journal of Sports Medicine and Physical Fitness, 57(12), 16601668. https://doi.org/10.23736/S0022-4707.17.06665-8.
Rose, E. A., Parfitt, G., \& Williams, S. (2005). Exercise causality orientations, behavioral regulation for exercise and stage of change for exercise: Exploring their relationships. Psychology of Sport and Exercise, 6(4), 399-414. https://doi.org/10.1016/j.psychsport.2004. 07.002 .

Ryan, R. M., \& Deci, E. L. (2020). Intrinsic and extrinsic motivation from a self-determination theory perspective: Definitions, theory, practices, and future directions. Contemporary Educational Psychology, 101860. https://doi.org/10.1016/j.cedpsych.2020. 101860.

Sicilia, Á., González-Cutre, D., Artés, E. M., Orta, A., Casimiro, A. J., \& Ferriz, R. (2014). Motivos de los ciudadanos para realizar ejercicio físico: un estudio desde la teoría de la autodeterminación. Revista Latinoamericana de Psicología, 46(2), 83-91. https://doi.org/10. 1016/S0120-0534(14)70011-1.

Silva, M. N., Markland, D. M., Vieira, P. N., Coutinho, S. R., Carraça, E. V., Palmeira, A. L., Minderico, C. S., Matos, M. G., Sardinha, L. B., \& Teixeira, P. J. (2010). Helping overweight women become more active: Need support and motivational regulations for different forms of physical activity. Psychology of Sports and exercise, 11(6), 591-601. https://doi.org/10.1016/j.psychsport.2010.06.011.

Standage, M., Gillison, F. B., Ntoumanis, N., \& Treasure, D. C. (2012). Predicting students' physical activity and health-related well-being: A prospective cross-domain investigation of motivation across school physical education and exercise settings. Journal of Sport and Exercise Psychology, 34(1), 37-60. https://doi.org/10.1123/ jsep.34.1.37.

Taylor, I. M., Spray, C. M., Ntoumanis, N., \& Standage, M. (2010). Motivational predictors of physical education students' effort, exercise intentions, and leisure-time physical activity: A multilevel linear growth analysis. Journal of Sport and Exercise Psychology, 32(1), 99-120. https://doi.org/10.1123/jsep.32.1.99.

Teixeira, P. J., Carraca, E. V., Markland, D., Silva, M. N., \& Ryan, R. M. (2012). Exercise, physical activity, and self-determination theory: A systematic review. International Journal of Behavioural Nutrition and Physical Activity., 9, 78. https://doi.org/10.1186/1479-5868-978.

Ullrich-French, S., Smith, A. L., \& Cox, A. E. (2011). Attachment relationships and physical activity motivation of college students. Psychology and Health, 26(8), 1063-1080. https://doi.org/10. 1080/08870446.2010.530123.

Vallerand, R. J. (1997). Toward a hierarchical model of intrinsic and extrinsic motivation. Advances in experimental social psychology. San Diego, CA: Academic Press.

Wang, J., \& Wang, X. (2012). Structural equation modeling: Applications using Mplus.Wiley on line library. https://doi.org/10. 1002/9781118356258.

Wilson, P. M., Rogers, W. T., Rodgers, W. M., \& Wild, T. C. (2006). The psychological need satisfaction in exercise scale. Journal of Sport \& Exercise Psychology, 28(3), 231-251. https://doi.org/10.1123/jsep. 28.3.231.

Yu, C. A., Rouse, P. C., Van Zanten, J. V. J., Metsios, G. S., Ntoumanis, N., Kitas, G. D., \& Duda, J. L. (2015). Motivation-related predictors of physical activity engagement and vitality in rheumatoid arthritis patients. Health psychology open, 2(2). https://doi.org/10.1177/ 2055102915600359.

Publisher's Note Springer Nature remains neutral with regard to jurisdictional claims in published maps and institutional affiliations. 